\title{
Cross-Ethnic Self-Disclosure Buffering Negative Impacts of Prejudice on International Students' Psychological and Social Well-Being
}

\author{
Tatsuya Imai ${ }^{\mathrm{a}}$ and Ayako Imai ${ }^{\mathrm{b}}$
}

\begin{abstract}
Intergroup contact theory suggests that developing a close relationship with outgroup members ameliorates the negative impact of prejudice that individuals perceive from outgroup members. This article specifically investigates the moderating role of cross-ethnic self-disclosure in the link between international students' perceived ethnic/racial prejudice and depression as well as loneliness. One hundred and forty-three international students in Japan were asked to rate their perceived prejudice, depression, and loneliness as well as their self-disclosure to host nationals. The results showed that self-disclosure buffers the negative effects of prejudice on depression and loneliness such that international students who were more likely to disclose themselves to host nationals were less likely to be influenced by prejudice. Theoretical and practical contributions are considered.
\end{abstract}

Keywords: depression, loneliness, personalization model, prejudice, self-disclosure

\section{Introduction}

According to the Organization for Economic Co-operation and Development (OECD, 2016), more than four million students were enrolled in education outside of their home countries in 2014 and the number has been increasing every year. International students can be defined as students who study at overseas educational institutions for specific purposes while being socially and culturally involved in a host country. As this definition implies, most international students not only focus on studying in a host country but also desire to broaden their horizons through cross-cultural experiences (Kitsantas, 2004). By accepting international students, host countries also receive tremendous benefits economically, culturally, intellectually, and politically (Bevis, 2002; Harrison, 2002).

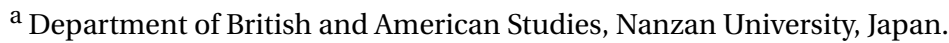

b Nanzan University, Japan.

${ }^{\circledR}$ Corresponding author: imatatsu@nanzan-u.ac.jp
} 
It should be noted, however, that many of the international students experience prejudice from host nationals because of their race and ethnicity (Hanassab, 2006; Lee \& Rice, 2007; Sam, 2001). One study assessing the experiences of international students studying in an American university showed that depending on the regions from which they originated, up to $46 \%$ of them reported that they had experiences of prejudice (Hanassab, 2006). Such perceived prejudice is associated with poor well-being of international students such as displaying depressive symptoms (e.g., Zhang \& Goodson, 2011). However, the negative effects of prejudice can be ameliorated if the targets of prejudice develop cross-ethnic friendship (e.g., Benner \& Wang, 2016). For example, if ethnic minorities in the U.S. have cross-ethnic friends, the negative impacts of prejudice on their psychological well-being were buffered (Benner \& Wang, 2016).

However, what kind of interaction (i.e., communication) those cross-ethnic partners need to engage in to alleviate the negative effects of prejudice is left unexplored. It is critical that people who are experiencing prejudice know strategies to ward off its negative effects. Using the personalization model developed by Brewer and Miller (1984), the current study focuses on a specific type of communication that might play the buffering role-self-disclosure. The personalization model argues that cross-ethnic self-disclosure may lead to positive intergroup attitudes. However, the possibility that cross-ethnic self-disclosure helps people alleviate the negative effects of perceived prejudice has not been fully investigated. This study specifically hypothesizes that for those international students who talk a lot about themselves with host nationals, the negative influence of prejudice on their depression and loneliness would be less significant compared to those who do not disclose information about themselves.

In the following section, the literature on situations of international students in Japan, which is the target country in this study, will be reviewed. Next, the literature on negative influences of prejudice that international students experience will be discussed. Then, using the personalization model, the reasons why cross-ethnic self-disclosure may play a buffering role in alleviating the negative impact of prejudice will be considered, followed by specific descriptions of the current study.

\section{Literature Review}

\section{International Students in Japan}

This study focuses on Japan as a target country because it has the ninth largest population of international students globally (Project Atlas, 2016). The number of international students in Japan was first recorded in 1983, and it was 10,428 (Suzuki, 2011). The number has been increasing every year and there were 267,042 international students in Japan in 2017 (Japan Student Services Organization, 2017). Most of them were from Asian countries (93.3\%) such as China and Vietnam, followed by European countries (3.2\%) like France and Germany, and the United States (1.2\%). In 2008, the Japanese government adopted a plan to increase the number of international students to 300,000 by 2020 , so educational institutions such as universities have tried to attract international students from different countries. 
However, previous literature found that some international students in Japan have negative experiences such as being a target of prejudice (Imai, 2017; Iwao \& Hagiwara, 1988; Maruyama, 1998; Sabetto \& Sabetto, 2010). Maruyama (1998) found that some international students in Japan reported that they were treated as foreigners who were not welcome by Japanese people. Imai (2017) revealed that some international students were aware that their home country and their compatriots were seen negatively by Japanese people. Sabatto and Sabatto (2010) interviewed international students in Japan and found that some international students had experiences of being treated unfairly due to their ethnicity and race.

Taken together, Japan has attempted to increase the number of international students, but it is not rare for them to be a target of prejudice. Besides the effort to increase the number of international students, Japan should make more effort to improve their quality of life while staying in Japan. Unfortunately, there has been little research on how international students could deal with prejudice either in Japan or in other countries. Thus, this study examines the roles of international students' communication that could ward off the negative effects of the prejudice that they experience. The next section introduces past studies researching the association between perceived prejudice and wellbeing among international students.

\section{International Students' Perceived Prejudice and Its Negative Effects}

Past studies show that prejudice experienced by international students has been associated with depression (e.g., Zhang \& Goodson, 2011). Wei, Russell, and Zakalik (2008) found that Asian international students in the US from China, India, Korea, Taiwan, and Hong Kong who perceived prejudice from Americans were more likely to experience depressive symptoms. The same association between perceived prejudice and depression was found for international students from India, Pakistan, and Bangladesh studying in the US (Rahman \& Rollock, 2004). Jung, Hecht, and Wadsworth (2007) also found the same association between the two variables for international students in the US and further revealed that the association was mediated by a personal-enacted identity gap, which is defined as the difference between an individual's self-concept and his or her expressed or performed identity in communication.

This study attempts to extend the previous findings regarding effects of perceived prejudice by predicting the association between perceived prejudice and loneliness. Richman and Leary (2009) suggested that perceived prejudice is harmful to the psychological well-being of the prejudiced because that individual feels socially excluded by outgroup members. Such feelings of being excluded are the main factor making those who are excluded feel lonely (de Jong Gierveld, van Tilburg, \& Dykstra, 2006). In the current study, outgroup members can be defined as host nationals because they are the ones who express prejudice against international students. For example, for an American student studying in Japan, outgroup members refer to Japanese people who could express prejudice against the American student. Therefore, international students who experience prejudice from host nationals may feel excluded, leading to loneliness. Based on previous studies on loneliness experienced by international students, Patron (2014) argued that prejudice could be a critical barrier that prevents international students from forming 
friendship with host nationals, and that may make them feel lonely. In line with this idea, Poyrazli and Lopez (2007) found that international students who experienced prejudice reported higher levels of homesickness, but little research has investigated the specific relationship between perceived prejudice and loneliness. Thus, the following hypothesis was posed:

- H1: International students' perceived prejudice is positively associated with their loneliness.

How could international students cope with the negative effect of prejudice? Some theories of intergroup contact help address the question.

\section{Intergroup Contact Theory}

Intergroup contact occurs when individuals belonging to one group interact with another group or its members (Sherif, 1966). One of the most influential theories of intergroup contact is the contact hypothesis developed by Allport (1954), arguing that interpersonal contact between different group members brings about positive attitudes toward a different group. The key idea of the theory is that positive effects of intergroup contact occur only if the following four conditions are met. First, interactants from different groups ideally have equal status. Second, they should pursue common goals. Third, to pursue the common goals, they should cooperate. Fourth, authority support is necessary to make the intergroup contact positive. Based on the contact hypothesis, Pettigrew (1998) developed intergroup contact theory (ICT) adding a fifth condition to the contact hypothesis: The contact situation should help interactants from different groups become friends. In other words, ICT suggests that cross-group friendships facilitate positive intergroup contact effects. Supporting the prediction, previous studies found that people who had outgroup friends such as those of another ethnicity and race reported a more favorable attitude toward the outgroup (Pettigrew, 1997; Powers \& Ellison, 1995). For example, participants in France, Great Britain, the Netherlands, and West Germany who had ethnic minority friends reported lower levels of prejudice toward ethnic minorities in general than those without such cross-ethnic friends (Pettigrew, 1997).

Integrating the theoretical accounts to the current study, it is possible for the crossgroup friendship to function as a moderator that alleviates negative impacts of prejudice on the recipients of prejudice. Even though participants were not international students, Benner and Wang (2016) investigated the possibility. They revealed that for racial and ethnic American minorities without cross-ethnic friends, those who perceived greater prejudice reported lower levels of psychological well-being. In contrast, for those who had one or more cross-ethnic friends, they reported greater psychological well-being and there was no significant association between perceived prejudice and psychological well-being. That is, cross-group friendships do buffer the negative effects of perceived prejudice on psychological well-being of the prejudiced.

However, past research has not assessed the specific forms of interaction that help people who perceive ethnic and racial prejudice buffer the negative effect of the experience. Benner and Wang (2016) found that having friends in different ethnic and racial groups wards off the negative effects of prejudice. Yet, is it still effective to have 
friends in different ethnic and racial groups if only shallow and superficial topics are discussed? It makes more sense that having friends with whom one can openly talk is more effective in buffering the negative influence of perceived prejudice. Therefore, this study examines cross-ethnic self-disclosure as a moderator that might buffer the negative effect of prejudice based on the personalization model.

\section{The Personalization Model and Cross-Group Self-Disclosure}

The personalization model was first formulated by Brewer and Miller (1984) and later elaborated on in other literature (e.g., Ensari \& Miller, 2005; Miller, 2002). Brewer and Miller (1984) discussed three types of ingroup contact: the category-based model, the differentiated model, and the personalization model. In the category-based model, the group boundaries are impermeable, so the differences between two distinct groups are salient. Thus, members in each group are seen stereotypically by outgroup members. In the differentiated model, group members are decategorized to some extent, so differences among each member within a group are more emphasized and group boundaries are more permeable. In the personalization model, group membership is less important, so differences of members within a group are clearer and similarities of members between groups are more salient. In such personalized interaction, each member's perception toward the outgroup members is favorable and their anxiety toward the outgroup members is moderated. Taken together, it is estimated that the negative impacts of prejudice should be ameliorated if two distinct groups are related to each other in accordance with the personalized model.

Such a personalized relation could be achieved through self-disclosure according to the personalization model (Ensari \& Miller, 2005; Miller, 2002). Self-disclosure can be defined as any information exchange regarding the self such as the discloser's thoughts, feelings, and experiences (Derlega \& Grzelak, 1979). Previous studies found some empirical evidence showing that self-disclosure functions to facilitate intergroup attitudes. Black participants who were interviewed by a White interviewer who disclosed intimate information showed greater liking for the White interviewer compared with the one who did not disclose intimate information (Berg \& Wright-Buckley, 1988). Further, the personalization achieved through self-disclosure is associated with a reduction of prejudice toward outgroup members such as those with different political views (Ensari \& Miller, 2005) and those with different religious beliefs (Ensari \& Miller, 2002). As described here, previous research assumes that cross-group self-disclosure may help the recipient of disclosure have a favorable attitude toward the outgroup that the discloser belongs to. Miller (2002) explained that the attitude change takes place because the disclosure may make the recipient perceive attraction (e.g., Archer, Berg, \& Runge, 1980) and liking (e.g., Worthy, Gary, \& Kahn, 1969) toward the discloser, thus leading to the positive attitude toward the outgroup as a whole. However, past studies of self-disclosure also imply that such cross-group self-disclosure might make the discloser have a positive attitude toward the outgroup that the recipient of disclosure belongs to. In line with this idea, selfdisclosure made the discloser have greater positive attitudes toward the recipient (G. R. Adams \& Sheam, 1981; Berg \& Archer, 1983). 
Overall, cross-group self-disclosure may help the discloser have a favorable attitude toward the outgroup. Specifically, self-disclosure could function as a moderator buffering the negative effects of perceived prejudice because past studies found that self-disclosure moderates the negative effects of stress on psychological well-being (e.g., R. E. Adams \& Cantin, 2013; Derlega, Metts, Petronio, \& Margulis, 1993). The current study investigates the effects of self-disclosure by international students because the negative impact of perceived ethnic/racial prejudice has been found to be significant in other studies (e.g., Rahman \& Rollock, 2004; Wei et al., 2008). Also, international students are aware of the salient boundaries that separate them from host nationals (Brisset, Safdar, Lewis \& Sabatier, 2010; Schmitt, Spears, \& Branscombe, 2003), so applying the personalization model to the intergroup relations between international students and host nationals is appropriate and effective.

This study focuses on depression and loneliness as consequences associated with perceived prejudice because depression (e.g., Zhang \& Goodson, 2011) and loneliness (e.g., Sawir, Marginson, Deumert, Nyland, \& Ramia, 2008) have been frequently assessed to measure international students' psychological and social well-being. Taken together, the following hypotheses are posed:

- H2: International students' self-disclosure to host nationals moderates the link between international students' perceived prejudice and depression.

- H3: International students' self-disclosure to host nationals moderates the link between international students' perceived prejudice and loneliness.

\section{Research Method}

This study was approved by the institutional review board of Nanzan University for research on human subjects. An online survey was used to assess international students in Japan regarding their perceived prejudice, the depth of and amount of their self-disclosure to host nationals, and their depression and loneliness.

\section{Participants}

One hundred and forty-six international students studying in Japan participated in this study, but data from three participants were dropped because they failed to answer some items involved in the analyses. Of the 143 participants, $54 \%(n=77)$ were male and $46 \%$ ( $n=66$ ) were female. Their ages ranged from 19 to 42 with the mean age at 27 . Most participants were from the United States $(n=23,16 \%)$, followed by China $(n=20,14 \%)$, India ( $n=12,8 \%)$, Indonesia ( $n=7,5 \%)$, England, Korea, Singapore, Philippines $(n=6$, $4 \%)$, Taiwan $(n=5,3 \%)$, and other countries $(n=52)$.

Some participants joined this study through a company for which they registered themselves as possible research participants and they received monetary incentives from the company for their participation. The others participated in this study through snowball sampling. That is, one of the authors personally asked international students he knew to take part in this survey. They were also asked to introduce this survey to other international students in Japan. 


\section{Measures}

The questionnaire included measures examining participants' perceived prejudice, the depth and amount of their self-disclosure to host nationals, and their depression, and loneliness. Study materials were available in English and Japanese. The reliabilities, means, and standard deviations for the measures as well as correlations among the variables are shown in Table 1 . The participants' sex and age were also asked in the questionnaire. None of the demographic information was correlated with other variables except for the negative correlation between age and depth of self-disclosure $(r=-.18, p=$ $.031)$ and amount of self-disclosure $(r=-.18, p=.036)$.

Table 1. Correlations among variables

\begin{tabular}{lcccccccc}
\hline & $\alpha$ & $M$ & SD & 1 & 2 & 3 & 4 & 5 \\
\hline Prejudice & .90 & 2.80 & 0.95 & - & & & & \\
$\begin{array}{l}\text { Depth of } \\
\text { self-disclosure }\end{array}$ & .81 & 2.94 & 1.02 & -.12 & - & & & \\
$\begin{array}{l}\text { Amount of } \\
\text { self-disclosure }\end{array}$ & .75 & 3.34 & 0.81 & $-.18^{*}$ & $.40^{* *}$ & - & & \\
$\begin{array}{l}\text { Depression } \\
\text { Loneliness }\end{array}$ & .80 & 1.99 & 0.52 & .16 & .34 & -.05 & - & \\
\hline
\end{tabular}

${ }^{*} p<.05,{ }^{* *} p<.01$.

\section{Perceived Prejudice}

Participants' perceived prejudice was assessed using a part of Acculturative Stress Scale for International Students developed by Sandhu and Asrabadi (1994). This original scale has 36 items examining various aspects of international students' acculturative stress, and this study used eight items among them that specifically assess respondents' perceptions of prejudice. Example items are "Others are biased toward me" and "I am denied what I deserve." A 5-point Likert scale was used $(1=$ strongly disagree, $5=$ strongly agree $)$, with higher scores indicating more perceived prejudice. The Cronbach's $\alpha$ was .90 .

\section{Depth and Amount of Self-Disclosure}

A part of self-disclosure scale developed by Wheeless (1976) was used to investigate the depth and amount of participants' self-disclosure to host nationals. Depth of selfdisclosure refers to how intimately and fully people talk about themselves (Wheeless, 1976). Amount of self-disclosure refers to how long and often people talk about themselves (Wheeless, 1976). Five items from the scale assess the depth of self-disclosure such as "I often disclose intimate, personal things about myself without hesitation" and "Once I get started, I intimately and fully reveal myself in my self-disclosure." Seven items assess the amount of self-disclosure such as "I usually talk about myself for fairly long periods at a time" and "I often talk about myself." A 5-point Likert scale was used ( 1 = strongly disagree, 
$5=$ strongly agree), with higher scores indicating more depth and amount of self-disclosure. The Cronbach's $\alpha$ of the depth scale was .81 and that of the amount scale was .75.

\section{Depression}

The 10-item version of the Center for Epidemiologic Studies-Depression Scale (CES-D; Radloff, 1977) was used to assess participants' depressive symptoms. Example items are "I felt that everything I did was an effort" and "My sleep was restless." To assess how frequently participants experienced each statement, a 4-point Likert scale was used (1 $=$ rarely or none of the time, $4=$ most or all of the time). Higher scores showed more depression and the Cronbach's $\alpha$ was .80.

\section{Loneliness}

The 10-item University of California, Los Angeles Loneliness Scale (Russell, 1996) was used to examine how lonely participants felt in a host country. Example items are "How often do you feel left out?" and "How often do you feel that people are around you but not with you?" A 4-point Likert scale was used $(1=$ never, $4=$ always $)$. Higher scores indicate more loneliness. The Cronbach's $\alpha$ was .82.

\section{Results}

As Table 1 shows, the association between perceived prejudice and depression was not statistically significant $(r=.16, p=.05)$, whereas prejudice was correlated with loneliness $(r=.41, p<.01)$.

Hypothesis 1 predicted the positive association between perceived prejudice and loneliness. Controlling for the effect of sex and age, results of multiple regression revealed that prejudice predicted loneliness, $b=0.21, \beta=0.42, t=5.48, p<.01$, which is consistent with H1.

Hypothesis 2 predicted that participants' self-disclosure to host nationals moderates the association between their perceived prejudice and depression. Specifically, for international students who disclose themselves less, those who perceive greater prejudice would report greater depressive symptoms. On the other hand, for international students who disclose themselves more, the relationship between prejudice and depression would be less significant. To test the interaction between prejudice and self-disclosure, multiple regression was conducted. All predictors were centered to avoid high multicollinearity involving the interaction term (Aiken \& West, 1991). Sex and age that were also centered were included in all the analyses as control variables.

To test H2, the model with predictors such as prejudice, depth of self-disclosure, and the interaction term (prejudice $\times$ depth of self-disclosure), and with the outcome of depression was formed. As Table 2 shows, results showed no main effect for prejudice $(b=0.08, \beta=0.15, t=1.75, p=.08)$ and depth of self-disclosure $(b=0.03, \beta=0.06, t=0.72$, $p=.47)$. An interaction between prejudice and depth of self-disclosure was significant, $b=$ $-1.11, \beta=-0.21, t=-2.48, p<.05$.

${ }^{*} p<.05,{ }^{* *} p<.01$. 
Table 2. Regression results: Depth of self-disclosure as a predictor

\begin{tabular}{lcccccc}
\hline \multicolumn{1}{c}{$\begin{array}{c}\text { Outcomes } \\
\text { Predictors }\end{array}$} & B & $\beta$ & $t$ & B & $\beta$ & $t$ \\
\hline & 0.08 & 0.15 & 1.75 & 0.20 & 0.40 & 0.08 \\
Prejudice & 0.03 & 0.06 & 0.72 & -0.01 & -0.02 & 0.03 \\
$\begin{array}{l}\text { Depth of self-disclosure } \\
\text { Prejudice } \times \text { depth }\end{array}$ & -0.11 & -0.21 & $-2.48^{*}$ & -0.06 & -0.13 & -0.11 \\
of self-disclosure & & & & & & \\
& & & & & & \\
\hline
\end{tabular}

Interactions are presented in Figure 1, in which high self-disclosure indicates $1 S D$ above the mean and low self-disclosure indicates $1 S D$ below the mean. Simple slope analyses revealed that prejudice predicted depression for those who did not disclose themselves deeply $(b=0.20, p<.01)$. However, prejudice did not predict depression for those who disclosed themselves deeply $(b=-0.03, p=.59)$. That is, depth of self-disclosure buffered the negative effect of prejudice on depression, so the results are consistent with $\mathrm{H} 2$.

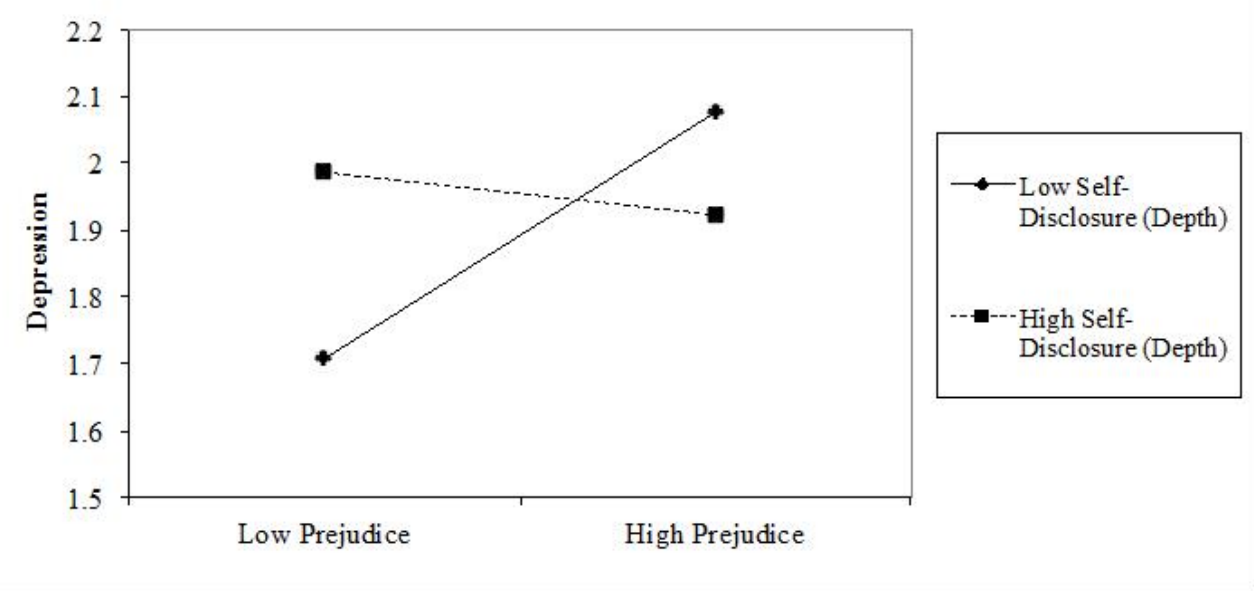

Figure 1. Simple slopes of effects for depth of self-disclosure on depression

Also, the model with predictors such as prejudice, amount of self-disclosure and the interaction term (prejudice $\times$ amount of self-disclosure), and the outcome of depression was formed. As Table 3 shows, results showed that none of the variables predicted depression, so the results are not consistent with $\mathrm{H} 2$.

To test H3, the model with predictors such as prejudice, depth of self-disclosure, and the interaction term (prejudice $\times$ depth of self-disclosure), and the outcome of loneliness 
was formed. As Table 2 shows, results showed that there was non-significant interaction effect ( $b=-0.06, \beta=-0.13, t=-1.71, p=.09$ ). Thus, the results are not consistent with H3.

Table 3. Regression results: Amount of self-disclosure as a predictor

\begin{tabular}{lcccccc}
\hline \multicolumn{1}{c}{\begin{tabular}{c} 
Outcomes \\
\multicolumn{1}{c}{ Predictors }
\end{tabular}} & B & $\beta$ & $t$ & B & $\beta$ & $t$ \\
\hline Prejudice & 0.09 & 0.16 & 1.86 & 0.19 & 0.39 & $5.08^{* *}$ \\
Amount of self-disclosure & 0.01 & 0.02 & 0.17 & -0.06 & -0.10 & -1.22 \\
Prejudice $\times$ amount & -0.08 & -0.13 & -1.41 & -0.10 & -0.16 & $-2.02^{*}$ \\
of self-disclosure & & & & & & \\
\hline
\end{tabular}

${ }^{*} p<.05,{ }^{* *} p<.01$.

Further, another model with predictors such as prejudice, amount of self-disclosure and the interaction term (prejudice $\times$ amount of self-disclosure), and with the outcome of loneliness was formed. As Table 3 shows, results showed a main effect for prejudice ( $b$ $=0.19, \beta=0.39, t=5.08, p<.01)$. There was a non-significant main effect for amount of self-disclosure ( $b=-0.06, \beta=-0.10, t=-0.87, p=.22$ ). An interaction between prejudice and amount of self-disclosure was significant, $b=-0.10, \beta=-0.16, t=-2.02, p<.05$. Interactions are presented in Figure 2, in which high self-disclosure indicates $1 S D$ above the mean and low self-disclosure indicates $1 S D$ below the mean. Simple slope analyses revealed that for both those who disclosed more and less about themselves, prejudice predicted loneliness. However, the effect for low self-disclosure $(b=0.27, p<.01)$ was more significant than that for high self-disclosure $(b=0.11, p<.05)$. Thus, amount of self-disclosure buffered the negative effects of prejudice on loneliness, so the results are consistent with H3.

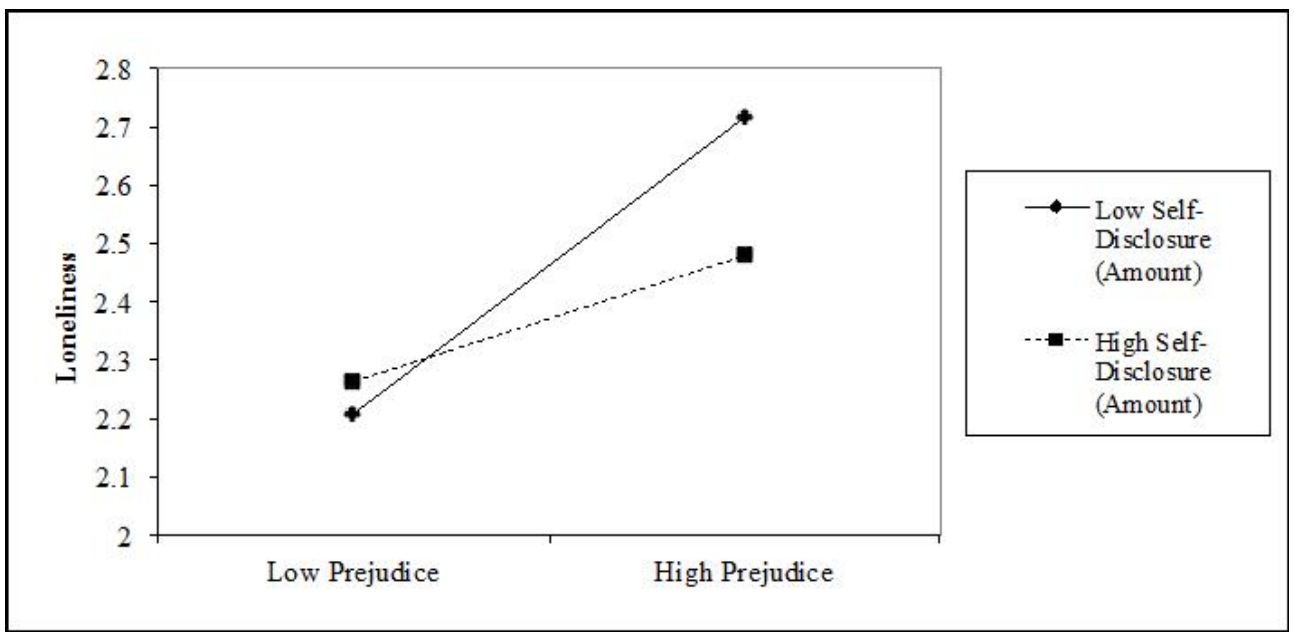

Figure 2. Simple slopes of effects for amount of self-disclosure on loneliness 


\section{Discussion}

While studying abroad provides students with many opportunities to mature and gain life experience, they often face difficulties of prejudice from host nationals. Past research indicates that developing a close relationship with cross-ethnic people may buffer the negative effect of prejudice on the well-being of those experiencing prejudice (Benner \& Wang, 2016). However, there is little research on the specific type of communication people from different groups should engage in to prevent perceived prejudice from damaging them. Therefore, this study specifically investigates the buffering role of crossethnic self-disclosure ameliorating the negative impact of prejudice on international students' psychological and social well-being. Results revealed that while depth of selfdisclosure by international students toward host nationals buffered the negative effects of prejudice on their depression, amount of self-disclosure buffered the negative effect of prejudice on their loneliness. The different buffering roles between depth and amount of self-disclosure will be discussed in the following section.

Depressive symptoms of international students have been considered a serious issue in previous research (for a review, see Zhang \& Goodson, 2011). However, how international students can deal with the symptoms through communication has not been fully examined. One of the contributions of this study is that the findings indicate the possibility that international students who feel depressed due to their experience of being prejudiced against may gain benefit from disclosing themselves deeply to host nationals. The effectiveness of deep self-disclosure reducing depressive symptoms has been found in previous studies. Gortner, Rude, and Pennebaker (2006) found that college students who disclosed their deepest thoughts and feelings on current and past emotional upheavals through writing reported lower depressive symptoms than those who wrote about their time management in a control condition. In the study conducted by Lepore (1997), participants who wrote their deepest thoughts and feelings about important exams they have to take showed a significant decline in depressive symptoms. Similarly, participants who wrote about their traumatic experiences exhibited a significant reduction in depressive symptoms than those who did not (Sloan, Marx, \& Epstein, 2005).

Further, in the area of psychotherapy, deep self-disclosure is considered effective in reducing a negative affect such as depression. Farber (2006) argued that psychiatric patients' deep self-disclosure to a therapist facilitates a therapeutic process. One of the reasons for the positive effect of deep self-disclosure is that the self-disclosure might help the patients gain greater insight into themselves and gain a more cohesive sense of self. Theoretically, perceived prejudice damages self-concept and self-esteem (Allport, 1954). Taken together, deep self-disclosure buffers the negative impact of perceived prejudice on international students' depression probably because disclosing their deep thoughts and feelings to host nationals may allow them to repair their damaged identity by believing that their identity is validated by the host nationals even though they experience prejudice. On the other hand, international students' deep self-disclosure did not alleviate the negative effect of prejudice on their loneliness. Reviewing past studies on self-disclosure, Bochner (1982) concluded that disclosing information that is too personal about oneself may not elicit liking from the recipient of disclosure. For example, Chaikin and Derlega (1974) 
found that intimate disclosure to an acquaintance was perceived to be less appropriate and more maladjusted than nondisclosure.

According to the results of the current study, what buffers the negative effect of prejudice on international students' loneliness is the amount of their self-disclosure to host nationals. Previous research suggests loneliness is one of the most serious issues of international students' social adjustment (Sawir et al., 2008). However, how international students overcome this difficulty through communication has not been fully researched. The results of this study indicate that if international students who feel lonely because of their experience of being prejudiced against could disclose themselves to host nationals, they could ward off the negative effect of prejudice on loneliness. Related to the results, a study conducted by Leung (2002) specifically revealed that participants' perceived loneliness was negatively associated with amount of their self-disclosure to others, but not with depth of their self-disclosure. Why is the amount rather than the depth of selfdisclosure effective in alleviating loneliness caused by prejudice? Past studies indicate that those who are prejudiced against feel socially excluded and the experience may make the recipient of prejudice lonely (de Jong Gierveld et al., 2006; Richman \& Leary, 2009). Therefore, to alleviate the negative impact of prejudice on loneliness, communication that allows the communicator to be involved with outgroup members without being rejected is necessary. A certain amount of self-disclosure without disclosing highly personal information would serve a role in helping the discloser build a relationship with the outgroup members (Bochner, 1982; Chaikin \& Derlega, 1974).

Another line of research on social capital shows that such light self-disclosure helps the discloser develop weak ties with others called "bridging social capital" (Parks, 1981; Putnam, 2000). While features of bonding social capital (i.e., strong ties) include emotionally close relationships such as close friends, those of bridging social capital (i.e., weak ties) include loose interpersonal connections among individuals who provide useful information or ideas with each other (Putman, 2000). Putman argues that bridging social capital rather than the bonding social capital is more typical when people from diverse social groups build relationships with each other. Considering various differences between international students and host nationals in values, beliefs, and customs, it is natural for international students to develop bridging social capital in order to prevent themselves from feeling lonely. Bian and Leung (2014) found such a negative correlation between bridging social capital and loneliness. To develop bridging social capital, international students' light self-disclosure (such as talking about their basic information without disclosing information that is too intimate) might be effective. These theoretical ideas may account for the findings of this study showing the amount of self-disclosure buffering the negative effect of prejudice on international students' loneliness.

\section{Limitations and Future Directions}

As for the first limitation, this study did not measure the content that participants talked about to host nationals. Specifically, this study assessed how much and how deeply international students talked about themselves, but it is still unclear what they shared with host nationals. The relevant, important question arises: Should international students talk about the experience of prejudice to host nationals? Past studies examining the effect 
of self-disclosure on the discloser's well-being suggests that they should talk about their thoughts and feelings directly related to the cause of stress (e.g., Lepore, 1997; Pennebaker, 1997; Sloan et al., 2005). For example, participants who wrote about their traumatic experiences reported reductions in depressive symptoms (Sloan et al., 2005). Therefore, it would be beneficial for international students to disclose their prejudice experiences to counteract the negative influence of that experience. However, international students might hesitate to talk about their experiences with prejudice to host nationals. So, who should they choose as the recipient of their self-disclosure? Would the effect of selfdisclosure vary depending on who they disclose themselves to? To address these various research questions, future studies should investigate other aspects of cross-ethnic selfdisclosure such as its contents and recipients.

Second, this correlational study does not make it possible to argue the causal relationships among variables. For instance, this study assumes that perceived prejudice causes loneliness. However, based on the results, it is also possible to argue that international students who feel lonely tend to perceive negative interaction with host nationals as prejudice. The possibility makes sense considering that people who feel isolated from others might be sensitive to reactions from others, so they may believe that they are unequally treated due to their personal characteristics such as race and ethnicity. Similarly, this study assumes that self-disclosure alleviates the negative effect of prejudice and leads to positive well-being, but it is also possible that people without psychological distress tend to talk about themselves because they are confident. To minimize the possibilities that are not consistent with the arguments of this study, several theoretical accounts are used such as a theory of interpersonal rejection (Richman \& Leary, 2009) and the personalization model (Brewer \& Miller, 1984). However, still, the results do not fully provide evidence of the causal relationships that this study hypothesizes.

To address this limitation, further experimental studies should be conducted. For example, participants who study abroad might be assigned to two groups: an experimental group or a control group. In the experimental group, participants would be asked to talk about themselves to a host national. In the control group, on the other hand, participants would be asked to talk about information that is not related to themselves to a host national confederate. After that, in both conditions, they would report their psychological well-being. It can be hypothesized that those in the experimental group would report more psychological well-being than those in the control condition.

However, the experimental design could not avoid criticism either. The main criticism lies in the generalizability of the results to natural settings in which international students interact with host nationals. The phenomena observed in the highly controlled setting in this experimental study might not occur in real interactions. Also, even if the results indicate that self-disclosure buffers the negative effect of prejudice in the experiment, it might not be ethical that some participants are not provided with the opportunity to disclose themselves. To improve the study design further, future studies should consider various methods including qualitative methods such as observation to carefully examine the influence of self-disclosure on perceived prejudice.

Finally, the generalizability of the current findings is limited because the sample of this study was only international students studying in Japan. International students in other 
countries that accept more international students such as the United States and Australia could have different experiences of prejudice.

\section{Implications}

To address the issue of prejudice that international students experience, educational institutions should first make stronger efforts to prevent prejudice from occurring in school. However, realistically, it is almost impossible to eliminate prejudice in schools where students from various national and cultural backgrounds study together. Therefore, it is more realistic and constructive to provide international students who experience prejudice with opportunities to cope with its negative effects. The results of this study may help educational institutions consider offering such opportunities. For example, most universities accepting international students have activities that help the students become involved with host nationals. However, most of the activities do not focus on international students who are worried about their experiences of prejudice. This study found that international students' self-disclosure with host nationals prevents the international students from feeling depressed or lonely. Thus, incorporating some activities in which international students could talk about themselves with host nationals should be effective in helping them adjust to life in a host country.

However, this study also revealed that disclosing themselves deeply did not alleviate the negative effects of prejudice on the loneliness international students experience. In line with these results, past research has indicated that highly intimate self-disclosure may not elicit liking from the recipient of disclosure (Bochner, 1982; Chaikin \& Derlega, 1974). Taken together, it may be critical for practitioners to encourage international students to disclose their less intimate information first and more intimate information as the relationship develops. The importance of the gradual development of interpersonal relationships is also argued for in social penetration theory (Altman \& Taylor, 1973). This theory emphasizes that less intimate self-disclosure is effective in the beginning stage of a relationship and the content of self-disclosure should be deepened as the relationship progresses.

Taken together, it is important for educational institutions to prepare opportunities for international students in which they are comfortable with talking about themselves with people from different countries, including host nationals. In reality, such opportunities are not fully provided. For instance, most international centers of universities in various countries provide opportunities for international students to interact with host nationals such as conversation partner programs, international coffee hour, and intercultural festivals. However, it may be difficult for international students to engage in satisfying conversation with others due to language and cultural barriers (Smith \& Khawaja, 2011). As a result, they may leave the activity feeling isolated and disappointed. The results of this study suggest that it is crucial for educational institutions to develop more structured programs in which international students are comfortable with disclosing themselves to others in an appropriate manner to ward off the negative effect of perceived prejudice. 


\section{Conclusion}

Even though past studies showed that many international students suffer from experiences of prejudice from host nationals (e.g., Zhang \& Goodson, 2011), there is little research examining strategies to alleviate the negative effects caused by their experiences with prejudice. Using various theories of intergroup contact, this study investigates the buffering role of international students' self-disclosure to host nationals in the association between their experiences of prejudice and their depression and loneliness. Results revealed that whereas depth of self-disclosure moderated the association between prejudice and depression, amount of self-disclosure moderated the association between prejudice and loneliness. The results may be helpful to refine programs for international students so that they could ward off the negative effects caused by prejudice. Future studies should be conducted to extend these findings by assessing the content of the selfdisclosure and examining different disclosure recipients.

\section{Funding}

This research is supported by Nanzan University [Pache I-A-2 grant, 2014]

\section{References}

Adams, G. R. \& Sheam, J. A. (1981). Talking and loving: A cross-lagged panel investigation. Basic \& Applied Social Psychology, 2, 81-88.

Adams, R. E. \& Cantin, S. (2013). Self-disclosure in friendships as the moderator of the association between peer victimization and depressive symptoms in overweight adolescents. Journal of Early Adolescence, 33, 341-362.

Aiken, L. S. \& West, S. G. (1991). Multiple regression: Testing and interpreting interactions. Sage, Newbury Park, CA.

Allport, G. (1954). The nature of prejudice. Doubleday Anchor, New York.

Altman, I. \& Taylor, D. (1973). Social penetration: The development of interpersonal relationships. Winston, New York: Holt, Rinehart.

Archer, R. L., Berg, J. H., \& Runge, T. E. (1980). Active and passive observers' attraction to a self-disclosing other. Journal of Experimental Social Psychology, 38, 120-130.

Atlas, P. (2016). A quick look at global mobility trends.

Benner, A. D. \& Wang, Y. (2016). Racial/ethnic discrimination and adolescents' well-being: The role of cross-ethnic friendships and friends' experiences of discrimination.

Berg, J. H. \& Archer, R. L. (1983). The disclosure-liking relationship: Effects of self perception, order of disclosure, and topical similarity. Human Communication Research, 10, 269-282.

Berg, J. H. \& Wright-Buckley, C. (1988). Effects of racial similarity and interviewer intimacy in a peer counseling analogue. Journal of Counseling Psychology, 35, 377-384.

Bevis, T. B. (2002). At a glance: International students in the United States. International Educator, 11, 12-17.

Bian, M. \& Leung, L. (2014). Smartphone addiction: Linking loneliness, shyness, symptoms and patterns of use to social capital. Media Asia, 41, 159-176. 
Bochner, A. P. (1982). On the efficacy of openness in closed relationships. In Burgoon, M., editor, Communication yearbook, volume 5, pages 109-124, New Brunswick, NJ. Transaction Books.

Brewer, M. B. \& Miller, N. (1984). Beyond the contact hypothesis: Theoretical perspectives on desegregation. In Miller, N. \& Brewer, M. B., editors, Groups in contact: The psychology of desegregation, pages 281-302, New York. Academic Press.

Brisset, C., Safdar, S., Lewis, J. R., \& Sabatier, C. (2010). Psychological and sociocultural adaptation of university students in France: The case of Vietnamese international students. International Journal of Intercultural Relations, 34, 413-426.

Chaikin, A. L. \& Derlega, V. J. (1974). Liking for the norm-breaker in self-disclosure. Journal of Personality, 42, 117-129.

Derlega, V. J. \& Grzelak, J. (1979). Appropriateness of self-disclosure. In Chelune, G. J., editor, Origins, patterns and implications of openness in interpersonal relationships, pages 151-176, San Francisco, CA. Jossey-Bass.

Derlega, V. J., Metts, S., Petronio, S., \& Margulis, S. T. (1993). Self-disclosure. Sage, Newbury Park, CA.

Ensari, N. \& Miller, N. (2002). Out-group must not be so bad after all: The effects of personalization, typicality and salience on intergroup bias. Journal of Personality and Social Psychology, 83, 313-329.

Ensari, N. \& Miller, N. (2005). Prejudice and intergroup attributions: The role of personalization and performance feedback. Group Process \& Intergroup Relations, 8, 391-410.

Farber, B. A. (2006). Self-disclosure in psychotherapy. Guilford Press, New York.

Gierveld, J. J., Tilburg, T., \& Dykstra, P. A. (2006). Loneliness and social isolation. In Vangelisti, A. \& Perlman, D., editors, The Cambridge handbook of personal relationships, pages 485-500, New York. Cambridge University Press.

Gortner, E., Rude, S. S., \& Pennebaker, J. W. (2006). Benefits of expressive writing in lowering rumination and depressive symptoms. Behavior Therapy, 37, 292-303.

Hanassab, S. (2006). Diversity, international students, and perceived discrimination: Implications for educators and counselors. Journal of Studies in International Education, 10, 157-173.

Harrison, P. (2002). Educational exchange for international understanding. International Educator, 11, 2-4.

Imai, T. (2017). How you see us hurts me! Influences of metastereotypes that international students hold on their self-disclosure, loneliness and depression. Journal of Intercultural Communication Research, 46, 385-399.

Iwao, S. \& Hagiwara, S. (1988). Foreign students studying in Japan: Social psychological analysis. The Keiso Shobo, Tokyo.

Jung, E., Hecht, M. L., \& Wadsworth, B. C. (2007). The role of identity in international students' psychological well-being in the United States: A model of depression level, identity gaps, discrimination, and acculturation. International Journal of Intercultural Relations, 31, 605-624.

Kitsantas, A. (2004). Studying abroad: The role of college students' goals on the development of cross-cultural skills and global understanding. College Student Journal, 
$38,441-452$.

Lee, J. J. \& Rice, C. (2007). Welcome to America? International student perceptions of discrimination. Higher Education, 53, 381-409.

Lepore, S. J. (1997). Expressive writing moderates the relation between intrusive thoughts and depressive symptoms. Journal of Personality and Social Psychology, 73, 1030-1037.

Leung, L. (2002). Loneliness, self-disclosure, and ICQ ("I seek you”) use. CyberPsychology \& Behavior, 5, 241-251.

Maruyama, M. (1998). Cross-cultural adaptation and host environment: A study of international students. in Japan (Doctoral dissertation.

Miller, N. (2002). Personalization and the promise of contact theory. Journal of Social Issues, 58, 387-410.

Organization, J. S. S. (2017). Results of survey on international students in 2017. Retrieved from.

Parks, M. R. (1981). Ideology in interpersonal communication: Off the couch and into the world. In Burgoon, M., editor, Communication yearbook, volume 5, pages 79-108, New Brunswick, NJ. Transaction Books.

Patron, M. (2014). Loss and loneliness among international students. Psychology Journal, 11, 24-43.

Pennebaker, J. W. (1997). Writing about emotional experiences as a therapeutic process. Psychological Science, 8, 162-166.

Pettigrew, T. F. (1997). Generalized intergroup contact effects on prejudice. Personality and Social Psychology Bulletin, 23, 173-185.

Pettigrew, T. F. (1998). Intergroup contact theory. Annual Review of Psychology, 49, 65-85.

Powers, D. A. \& Ellison, C. G. (1995). Interracial contact and Black racial attitudes: The contact hypothesis and selectivity bias. Social Forces, 74, 205-226.

Poyrazli, S. \& Lopez, M. D. (2007). An exploratory study of perceived discrimination and homesickness: A comparison of international students and American students. The Journal of Psychology, 141, 263-280.

Putnam, R. D. (2000). Bowling alone. Simon \& Schuster, New York.

Radloff, L. S. (1977). The CES-D Scale: A self-report depression scale for research in the general population. Applied Psychological Measurement, 1, 385-401.

Rahman, O. \& Rollock, D. (2004). Acculturation, competence, and mental health among South Asian students in the United States. Journal of Multicultural Counselling and Development, 32, 130-140.

Richman, L. S. \& Leary, M. R. (2009). Reactions to discrimination, stigmatization, ostracism, and other forms of interpersonal rejection: A multimotive model. Psychological Review, 116, 365-383.

Russell, D. (1996). The UCLA Loneliness Scale (Version 3): Reliability, validity, and factor structure. Journal of Personality Assessment, 66, 20-40.

Sabetto, M. \& Sabetto, Y. (2010). Culture shock in Japan: International student perspective. Chigensha, Saitama, Japan.

Sam, D. L. (2001). Satisfaction with life among international students: An exploratory study. Social Indicator Research, 53, 315-337. 
Sandhu, D. S. \& Asrabadi, B. R. (1994). Development of an acculturative stress scale for international students: Preliminary findings. Psychological Reports, 75, 435-448.

Sawir, E., Marginson, S., Deumert, A., Nyland, C., \& Ramia, G. (2008). Loneliness and international students: An Australian study. Journal of Studies in International Education, 12, 148-180.

Schmitt, M. T., Spears, R., \& Branscombe, N. R. (2003). Constructing a minority group identity out of shared rejection: The case of international students. European Journal of Social Psychology, 33, 1-12.

Sherif, M. (1966). In common predicament: Social psychology of intergroup conflict and cooperation. Houghton Mifflin, Boston.

Sloan, D. M., Marx, B. P., \& Epstein, E. M. (2005). Further examination of the exposure model underlying the efficacy of written emotional disclosure. Journal of Consulting and Clinical Psychology, 73, 549-554.

Smith, R. A. \& Khawaja, N. G. (2011). A review of the acculturation experiences of international students. International Journal of Intercultural Relations, 35, 699-713.

Suzuki, Y. (2011). Situations of international students and education for them in Japan. Shunpusha, Yokohama, Japan.

Wei, M. F., Russell, D. W., \& Zakalik, R. A. (2005). Adult attachment, social self-efficacy, self-disclosure, loneliness, and subsequent depression for freshman college students: A longitudinal study. Journal of Counseling Psychology, 52, 602-614.

Wheeless, L. R. (1976). Self-disclosure and interpersonal solidarity: Measurement, validation, and relationships. Human Communication Research, 3, 47-61.

Worthy, M., Gary, A. L., \& Kahn, G. M. (1969). Self-disclosure as an exchange process. Journal of Personality and Social Psychology, 13, 59-63.

Zhang, J. \& Goodson, P. (2011). Predictors of international students' psychosocial adjustment to life in the United States: a systematic review. International Journal of Intercultural Relations, 35, 139-162.

\section{Author biography}

Tatsuya Imai is an assistant professor in the Department of British and American Studies at Nanzan University. His research interests include acculturation, prejudice, and intercultural communication.

Ayako Imai Her research interests lie in the area of intercultural communication, focusing on international students' adjustment. 